\title{
Do Intermediate Monolinguals and Bilinguals Use Different Learning Strategies?
}

\author{
Asieh Seifi \\ Department of English, Golestan Payam Noor University, Iran \\ E-mail: seifi_a61@yahoo.com \\ Seyed Jalal Abdolmanafi Rokni (Corresponding author) \\ Department of English, Golestan University, Iran \\ E-mail: j.abdolmanafi@gmail.com
}

Received: October 21, 2013 Accepted: November 11, $2013 \quad$ Published: November 11, 2013

doi:10.5296/ijele.v2i1.4542 URL: http://dx.doi.org/10.5296/ijele.v2i1.4542

\begin{abstract}
This study investigated the difference between Iranian monolingual and bilingual language learners with intermediate level of language proficiency in terms of language learning strategies. The participants of this study were 50 students who were randomly selected from some universities in Golestan province. There were 25 monolinguals (Persian speakers) and 25 bilinguals (Turkmen-Persian speakers). The findings revealed that bilinguals had an advantage over monolinguals in terms of using strategies. They used more cognitive and metacognitive strategies. Moreover, the findings showed that bilinguals and monolinguals had a little different preference in using strategies. Bilinguals used metacognitive, social, cognitive, affective, compensation and memory strategies, respectively, while monolinguals used metacognitive, cognitive, social, affective, compensation and memory strategies, respectively.
\end{abstract}

Keywords: Language learning strategies, Bilingualism, Monolingualism, Persian, Turkmen

\section{Introduction}

Over the last few decades, a gradual but significant shift of attention has taken place within the field of education, resulting in less emphasis on teachers and teaching to greater emphasis on learners and learning. At the same time, a shift of attention has taken place in second language acquisition research from the products of language learning to the processes through which learning takes place (Oxford, 1990). Many research studies have investigated learner 
characteristics and in an effort to lead learners towards autonomous and independent language learners, research in second language acquisition has largely focused on learner centered approaches to second language teaching (Tamada, 1996). As a result of this change, language learning strategies have emerged not only as integral components of various theoretical models of language proficiency (Ellis, 1985) but also as a means of achieving learners' autonomy in the process of language learning (Oxford, 1990).

However, what exactly is meant by the term learning strategy? Wenden (1987) defined learning strategies as the various operations that learners use in order to make sense of their learning. Williams and Burden (1997) indicated that when students are involved in a learning task, they have several resources which they use in different ways to finish or solve the task, so this can be termed process of learning strategy. In other words, learning strategy is learning skills, learning-to-learn skills, thinking skills, problem skills or the methods which learners use to intake, store, and retrieve during the learning process. Oxford (1990) defines learning strategies as "specific actions taken by the learner to make learning easier, faster, more enjoyable, more self-directed, more effective, and more transferable to new situations". So learners use learning strategies to learn things more successfully.

The frequent use of learning strategies in language classrooms turns out to be a significant factor in the success of EFL learners, which may contribute to further aspects involved in second language acquisition so the relationship between language learning strategies and other aspects such as age, sex, attitude, motivation, aptitude, learning stage, task requirements, teacher expectation, learning styles, individual differences, motivation, cultural differences, beliefs about language learning, and language proficiency in the process of acquisition has been investigated.

The investigation about bilingual and mostly monolingual students' use of learning strategies is one of them and they were conducted all over the world. Most participants of previous researches especially in the USA were monolingual, however, it is easy to find many bilingual or monolingual language learners all over the world. It can be expected from them to be good at languages as they acquire more languages when compared with the monolingual language learners.

As Rivers (2001) stated, the popular belief that bilinguals or multilinguals learn a subsequent language more easily than monolinguals has received substantial attention from researchers in recent years. Further, minority language communities in the European Union achieve greater educational autonomy and United State Government language training programs seek to respond to rapidly changing requirements for global expertise.

This study was an attempt to investigate the difference between monolingual and bilingual foreign language learners in terms of use of learning strategies while learning a new language. The following questions guided the present study:

1-Do Iranian monolingual and bilingual foreign language learners differ in using learning strategies while learning a foreign language?

2-How do Iranian bilingual and monolingual foreign language learners differ in using 
learning strategies while learning a foreign language?

\section{Background}

Research into language learning strategies has increased significantly since the 1970s, because such categories play various important roles in language learning (Lee, 2010). Many researchers have got interested in the kinds of strategies language learners use to understand, learn or remember the information in the area of second or foreign language learning and the way of information processing. For instance, Naiman et al. (1978) pointed out that certain learners are more successful than others at learning a second or foreign language despite exposure to the same teaching methods and learning environment. Therefore, in an attempt to make this concept clear, the term language learning strategy has been highlighted by a number of researchers and then various definitions were presented based on different points of view.

Brown and Palinscar (1982) categorized language learning strategies into cognitive, metacognitive and social-affective strategies. According to Wenden (1987), language learning strategies can be defined from the aspect of language learning behaviors, such as learning and regulating the meaning of a second or foreign language, cognitive theory, such as learners' strategic knowledge of language learning, and the affective view, such as learners' motivation, attitude, etc. It is argued that these three points of views can improve language learning.

O'Malley et al. (1985) studied the use of learning strategies by ESL learners in the US. Based on their research, language learning strategies were divided into three main categories, metacognitive, cognitive, and social affective which refer to learners' planning their learning, thinking about the learning process, monitoring their own comprehension or production, and evaluating the outcomes of their own learning. They found that most importance was given to the metacognitive strategies (i.e., those that deal with planning, directing or monitoring).

Oxford (1990), one of the first to undertake research in this area, describes language learning strategies as techniques consciously used by learners to improve their progress in acquiring, storing, retaining, and using information in second or foreign language. Oxford (1989) in her Strategies Inventory for Language Learning (SILL) emphasized six categories namely, memory strategies (e.g., grouping, representing sounds in memory), cognitive strategies (e.g., repeating, analyzing, getting the idea quickly and taking notes), compensation strategies (e.g., switching to the mother tongue, using other clues), metacognitive strategies (e.g., linking new information with already known one, self-monitoring), affective strategies (lowering anxiety by use of music, encouraging oneself and discussing feelings with others) and social strategies (asking for clarification, cooperating with others and developing cultural understanding).

As mentioned above, the definition by Oxford (1990) included cognitive, emotional, and social aspects of language learning strategies that enhance learners' language learning proficiency and self-confidence (Oxford, 1990). Oxford (1990) stated that language learning strategies have such features as contributing to the main goal (communicative competence), allowing learners to become more self-directed, expanding the role of teachers, being 
problem oriented, being specific actions taken by the learners, involving many aspects of the learner, supporting learning both directly and indirectly, not being always observable, being often conscious, can be taught, being reflexive, being influenced by a variety of factors. Therefore, when language learners encounter language learning tasks such as reading or writing, they can apply some different strategies to complete the tasks. Language learners will be successful in the tasks due to the use of an appropriate language learning strategy (Richard, 1992).

As mentioned earlier, many researchers have studied language learning strategies and factors related to choice and use of language learning strategies such as learners' motivation, learning style, cultural backgrounds, gender, and nationality. Oxford and Nyikos (1989) explored the relationship between language learners' proficiency and their use of strategy use as well. They used SILL to investigate strategies used by 1200 students of university who studied five different foreign languages. They found that different backgrounds affected use of language learning strategies. Moreover, students' self-rating of proficiency levels was closely linked to their use of language learning strategies.

Vann and Abraham (1990) carried out research into successful and unsuccessful language learners. The results of their studies revealed that unsuccessful learners did use strategies generally considered as useful, and often they employed the same strategies as successful learners. However, the difference is that successful learners used strategies more appropriately in different situations than unsuccessful learners. They also used a larger range of strategies in language learning more frequently and appropriately. Ehrman and Oxford (1995) found that only cognitive strategies had a significant relationship with language proficiency in the SILL category. Other strategies such as memory, compensation, metacognitive, affective, and social strategies had no significant relationship with proficiency.

Most of these investigation about the use of language learning strategies have generally been conducted in countries where English is the official language like the USA. However, not many studies have been conducted about the use of learning strategies in other countries where bi- or monolingual speakers are available (Tuncer, 2009). Wharton (2000) maintains that researchers have mostly examined strategy use outside the United States and they have generally used English as a foreign language (EFL) and ESL students (generally monolingual) as their participants. It has been stated by researchers that knowledge of more than one language facilitates the acquisition of additional languages. Supporting this claim, Hakuta (1990) stated that bilingualism can lead to superior performance on a variety of intellectual skills.

As Iran is one of the countries with a lot of bilingual inhabitants in the border areas: Kords, Turkmens, Azaris, Arabs, and considering the fact that English is one of the main courses in public curriculum in Iran, having more information about the differences between Iranian bilingual and monolingual students seems an important case. If it is approved that bilinguals, compared to monolinguals, use some learning strategies more or in different order, it can help teachers to encourage students to use more effective ones and sometimes teach effective strategies directly. Further, it can be helpful for learners to learn faster and easier and access 
learning objectives more quickly. Considering different bilingual communities in Iran and their different linguistic features studies like this can be helpful for teachers and students.

Most researchers in the area of language acquisition believe in the facilitative role of previous linguistic experience in language learning. It is claimed that especially in third language acquisition it can be found in the area of metacognition. The experience of learning another language may later employ the learner's metacognitive self-assessment and self-management and provide the learner with explicit, declarative metalinguistic knowledge about how languages work (Rivers and Golonka, 2009).

Another facilitative role of previous linguistic knowledge refers to Learner autonomy. River and Golonka (2009) define learner autonomy as the active, independent management of learning by the learner (rather than independent study outside the classroom), where the learner sets or attempts to control the goals, curriculum, pedagogical method, or content of the learning program.

The first factor which seems facilitative is metalinguistic awareness. Some studies have been done in this area. The first researcher was Ramsay (1980) who discovered that multilinguals tended to perform far better than monolinguals on an achievement test. Successful learners in Ramsay's study tended to use more cognitive and metacognitive strategies including substantially more verbalization and vocal practice, use of mnemonic devices, a more positive attitude toward the learning process (an affective strategy), and more risk taking and less fear of errors. Ramsay noted that metacognitive strategies can be distinguished as the primary difference between novice and expert learners across a broad set of abstract systems of knowledge, specifically in language, at both a very discrete level (the processing of specific constituent units) and a discourse level.

Moreovee, Wenden (1999) reviewed literature on metacognition in language learning and drew a similar conclusion that good language learners as well as self-directed language learners exhibit metacognitive behaviors.

Further, Möhle (1989) examined learning strategies in German multilingual university students. Taking a variety of Indo-European languages (French, Spanish, and English), she hypothesized that the narration of a film with no overt linguistic information would be influenced by cognitive processing. Also, she found evidence of controlled lexical transfer, again a metacognitive strategy. Metalinguistic awareness is believed to play an important role in L3 acquisition.

In addition, Bartlet (1989) examined the influence of L3 on procedural (metalinguistic) knowledge in a case study on interference in L3 (English) from L2 (Spanish) among multilingual Yaqui Indians in Arizona. Bartlet found evidence of broad use of metacognitive and communicative strategies in oral discourse and oral narrative.

Moreover, Jessner (1999) investigated the role of metalinguistic awareness in multilinguals within the framework of the Dynamic Model of Multilingualism. She analyzed qualitative data collected from trilingual adults via think-aloud protocol sessions to illustrate different strategies learners use in searching for a word in L3. Jessner provided examples of code 
switching involving either two or three languages along with learners' attempts to look for equivalents or cognates in the three languages. Jessner argued that metalinguistic awareness is desirable and can be increased through teaching similarities between languages and through activating students' prior linguistic knowledge.

Further, two other studies carried out by Zobl (1992) and Klein (1995) attributed better performance of multilinguals than monolinguals on grammaticality judgment tests to metalinguistic awareness.

In case of learner autonomy some research studies have been conducted. One of them was Rivers (1996) who compared proficiency outcomes of L3 learners from three programs: a program in languages of the former Soviet Union at the University of Maryland, a cross-training program at the Defense Language Institute (DLI), and a DLI study of immersion training with learners enrolled in L2 courses. A qualitative method was applied by Rivers (2001) using a variety of data-collection techniques, including questionnaires, focus groups, classroom observation, and interviews, to investigate the characteristics and behaviors of college students learning a third language. He found that L3 learners were more successful than L2 learners of the same target language; that is, they learned more of the language in a shorter time than L2 learners, based on end-of-course proficiency tests administered by DLI and other USG agencies.

In another study, Rivers (2001) analyzed self-directed language learning behaviors of 11 adult learners of Georgian and Kazakh as a third language. All subjects' L1 was English and all had advanced proficiency in L2 Russian. Rivers found that all learners accurately assess their progress, learning styles, and learning strategy preferences, as well as conflicts with teaching styles and behaviors of other learners within the class. Next, based upon these self-assessments of learner styles and preferences, all learners revealed a high tendency toward controlling their learning process, the tendency toward learner autonomy being demonstrated by their requesting and demanding changes to course content and structure. Finally, the majority of learners made attempts to modify the learning environment by using self-directed language learning strategies that referred to different aspects of course structure, for example, type and mode of input, workload, and classroom activities.

\section{Methodology}

\subsection{Setting and Participants}

This study was designed to examine the effect of bilingualism and monolingualism on using learning strategies among Iranian students. Fifty intermediate level students were selected from some universities in Golestan province, Iran during the spring semester in 2013. They were non-English major students aged 18-23. Having studied English as a foreign language for at least five years, they were taking general English courses at the university. All the participants were Iranians but the sample was not ethnically the same. Monolinguals' first language was Persian but the first language of bilinguals was Turkmen and their second language was Persian. They all voluntarily took part in the study and gave consent for data collection. The students were all selected randomly. 


\subsection{Instrumentation}

In order to collect information on strategy use, Oxford's (1990) 50-item Strategy Inventory for Language Learning (SILL, version 7.0) is adapted for the study. The SILL was developed by Rebecca Oxford (1990) as an instrument for assessing the frequency of use of language learning strategies by students. It is a 50-item Likert-type questionnaire with five-scale responses regarding the six major strategy groups as distributed in Table 1. According to Oxford (1990) classification, learners with the mean of 3.5 or more were considered as high strategy users, learners with the mean of below 2.4 are low strategy users and the mean for medium strategy users is between 2.4 and 3.5.

Table 1. Distribution of strategy items according to the six strategy types

\begin{tabular}{|l|l|l|}
\hline Strategy Type & Items & Total \\
\hline Memory & $1-9$ & 9 \\
\hline Cognitive & $10-23$ & 14 \\
\hline Compensation & $24-29$ & 6 \\
\hline Metacognitive & $30-38$ & 9 \\
\hline Affective & $39-44$ & 6 \\
\hline Social & $45-50$ & 6 \\
\hline & & 50 \\
\hline
\end{tabular}

The items were in the form of statements and the participants graded them from 1 to 5 where:

1- means never true of me.

2- means rarely true of me.

3- means sometimes true of me.

4- means usually true of me.

5 -means always true of me.

It appears that SILL is the 'most often used strategy scale around the world', and the only language learning strategy instrument that has been checked for reliability and validated in multiple ways (Oxford \& Burry-Stock, 1995). As a result, researchers have been working on the factors that affect language learning strategy use, and these studies not only indicate variables affecting learning strategy but also contribute to the field of investigation into language learning strategies.

\subsection{Procedure}

In the beginning of the process, the students in the two groups were asked to take a pretest to ensure that both groups are homogeneous in language proficiency. This test was a validated proficiency test according to the standards of Top Notch Book Series. Then two informal meetings were held (one with monolinguals and the other with bilinguals) to make students 
aware of the purpose of the study. The researcher explained about language learning strategies and emphasized that it is just research and the result does not have any effects on their positions. None of the two groups knew about comparison nature of the study; in fact, none of them knew that they were going to be compared with another group. The reason was to avoid any types of bias in answering questions.

\section{Results}

Data elicited from students' responses to each item in the SILL were analyzed by using a descriptive statistics, Cramer's test and a t-test. The results are as follow:

Table 2 shows 25 monolingual EFL students' responses to language learning strategies. Monolingual students used metacognitive, cognitive/social, affective, compensation and memory strategies, respectively. The monolingual EFL students reported medium use of strategy categories, as the mean of overall strategy use was 2.2 .

Table 2. Frequency of Language Learning Strategies Used by Monolingual Students

One-Sample Statistics

\begin{tabular}{|l|l|c|c|c|}
\hline & $\mathrm{N}$ & Mean & Std. Deviation & Std. Error Mean \\
\hline memory & 25 & 1.6000 & .50709 & .13093 \\
cognitive & 25 & 2.4000 & .50709 & .13093 \\
compensation & 25 & 1.7333 & .79881 & .20625 \\
metacognitive & 25 & 2.6000 & .50709 & .13093 \\
affective & 25 & 2.2000 & .77460 & .20000 \\
social & 25 & 2.4000 & .50709 & .13093 \\
total & 25 & 2.2000 & .41404 & .10690 \\
\hline
\end{tabular}

According to descriptive analysis, and as can be observed in Table 3, bilingual students used metacognitive, social, cognitive, affective, compensation and memory strategies respectively. The bilingual EFL students reported medium use of strategy categories, as the mean of overall strategy use was 2.73 .

Table 3. Frequency of Language Learning Strategies Used by Bilingual Students

One-Sample Statistics

\begin{tabular}{|l|l|c|c|c|}
\hline & $\mathrm{N}$ & Mean & Std. Deviation & Std. Error Mean \\
\hline memory & 25 & 2.3333 & .48795 & .12599 \\
cognitive & 25 & 2.7333 & .45774 & .11819 \\
compensation & 25 & 2.5333 & .51640 & .13333 \\
metacognitive & 25 & 2.8667 & .41404 & .10690 \\
affective & 25 & 2.6000 & .50709 & .13093 \\
social & 25 & 2.8000 & .35187 & .09085 \\
total & 25 & 2.7333 & .45774 & .11819 \\
\hline
\end{tabular}


Considering the means of language learning strategy use among monolinguals and bilinguals of intermediate level, both groups were considered as medium strategy users but bilinguals had to some extent an advantage over monolinguals and used more metacognitive and cognitive strategies.

Table 4. Group Statistics

\begin{tabular}{|l|l|c|c|c|c|}
\hline & Language & $\mathrm{N}$ & Mean & Std. Deviation & Std. Error Mean \\
\hline \multirow{2}{*}{$\mathrm{re}$} & Bilinguals & 25 & 2.7333 & .45774 & .11819 \\
\cline { 2 - 6 } & Monolinguals & 25 & 2.2000 & .41404 & .10690 \\
\hline
\end{tabular}

According to independent t-test in Table 5, since Levene's Test for Equality of Variances is 0.70 with significant level of 0.40 , the analysis indicates Equal Variances assumed. In this study t- test equals 3.34 with significant level of 0.002 . Thus according to retrieved data, there was a significant difference in using language learning strategies among monolinguals and bilinguals. Detailed information about each group has been presented in Tables 6 and 7 .

Table 5. Independent Samples Test of Monolingual Students

\begin{tabular}{|c|c|c|c|c|c|c|c|c|c|}
\hline & \multicolumn{9}{|c|}{$\begin{array}{l}\text { Levene's Test } \\
\text { for Equality oft-test for Equality of Means } \\
\text { Variances }\end{array}$} \\
\hline & \multirow[t]{2}{*}{$\mathrm{F}$} & \multirow[t]{2}{*}{ Sig. } & \multirow[t]{2}{*}{$t$} & \multirow[t]{2}{*}{ df } & \multirow[t]{2}{*}{$\begin{array}{l}\text { Sig. } \\
\text { (2-tailed) }\end{array}$} & \multirow[t]{2}{*}{$\begin{array}{l}\text { Mean } \\
\text { Difference }\end{array}$} & \multirow[t]{2}{*}{$\begin{array}{l}\text { Std. Erro } \\
\text { Difference }\end{array}$} & \multicolumn{2}{|c|}{$\begin{array}{l}95 \% \text { Confidenc } \\
\text { Interval of th } \\
\text { Difference }\end{array}$} \\
\hline & & & & & & & & Lower & Upper \\
\hline $\begin{array}{l}\text { Equal } \\
\text { variances } \\
\text { assumed }\end{array}$ & .707 & .408 & 3.347 & 728 & .002 & .53333 & .15936 & .20689 & .85978 \\
\hline $\begin{array}{l}\text { Equal } \\
\text { variances } \\
\text { not assumed }\end{array}$ & & & 3.347 & 727.723 & .002 & .53333 & .15936 & .20674 & .85992 \\
\hline
\end{tabular}


Table 6. One-Sample Test of Bilingual Students

\begin{tabular}{|c|c|c|c|c|c|c|}
\hline & \multicolumn{6}{|c|}{ Test Value $=0$} \\
\hline & \multirow[t]{2}{*}{$t$} & \multirow[t]{2}{*}{ df } & \multirow{2}{*}{\multicolumn{2}{|c|}{\begin{tabular}{|l|l} 
Sig. (2-tailed) & $\begin{array}{l}\text { Mean } \\
\text { Difference }\end{array}$
\end{tabular}}} & \multicolumn{2}{|c|}{$\begin{array}{l}95 \% \text { Confidence Interval of } \\
\text { the Difference }\end{array}$} \\
\hline & & & & & Lower & Upper \\
\hline Memory & 18.520 & 24 & .000 & 2.33333 & 2.0631 & 2.6036 \\
\hline Cognitive & 23.127 & 24 & .000 & 2.73333 & 2.4798 & 2.9868 \\
\hline Compensation & 19.000 & 24 & .000 & 2.53333 & 2.2474 & 2.8193 \\
\hline Metacognitive & 26.192 & 24 & .000 & 2.86677 & 2.5707 & 3.0293 \\
\hline Affective & 19.858 & 24 & .000 & 2.60000 & 2.3192 & 2.8808 \\
\hline social & 31.553 & 24 & .000 & 2.8000 & 2.6718 & 3.0615 \\
\hline Total & 23.127 & 24 & .000 & 2.73333 & 2.4798 & 2.9868 \\
\hline
\end{tabular}

Table 7. One-Sample Test of Bilingual and Monolingual Students

\begin{tabular}{|c|c|c|c|c|c|c|}
\hline & \multicolumn{6}{|c|}{ Test Value $=0$} \\
\hline & \multirow[t]{2}{*}{$\mathrm{T}$} & \multirow[t]{2}{*}{$\mathrm{df}$} & \multirow{2}{*}{$\begin{array}{l}\text { Sig. } \\
\text { (2-tailed) }\end{array}$} & \multirow{2}{*}{$\begin{array}{l}\text { Mean } \\
\text { Difference }\end{array}$} & \multicolumn{2}{|c|}{$\begin{array}{l}95 \% \text { Confidence Interval of } \\
\text { the Difference }\end{array}$} \\
\hline & & & & & Lower & Upper \\
\hline memory & 12.220 & 24 & .000 & 1.60000 & 1.3192 & 1.8808 \\
\hline cognitive & 18.330 & 24 & .000 & 2.40000 & 2.1192 & 2.6808 \\
\hline Compensation & 8.404 & 24 & .000 & 1.73333 & 1.2910 & 2.1757 \\
\hline Metacognitive & 19.858 & 24 & .000 & 2.60000 & 2.3192 & 2.8808 \\
\hline affective & 11.000 & 24 & .000 & 2.20000 & 1.7710 & 2.6290 \\
\hline social & 18.330 & 24 & .000 & 2.40000 & 2.1192 & 2.6808 \\
\hline total & 20.579 & 24 & .000 & 2.20000 & 1.9707 & 2.4293 \\
\hline
\end{tabular}

Since one of variables is nominal (language) and the other is ordinal (learning strategies), Cramer's test was chosen for analysis. According to Cramer's test, level of significance is 0.003 which is lower than 0.05 . So the result of test was significant and reliable and bilinguals used language learning strategies more than monolinguals.

Table 8. re * language Crosstabulation

Count

\begin{tabular}{|ll|l|l|l|}
\hline & & \multicolumn{2}{l}{ language } & Total \\
\cline { 2 - 5 } & Bilinguals & Monolinguals & \\
\hline \multirow{2}{*}{ skill } & 7 & 18 & 25 \\
\hline \multirow{2}{*}{ Total } & 18 & 7 & 25 \\
\hline
\end{tabular}


Table 9. Symmetric Measures

\begin{tabular}{|l|l|l|l|}
\hline \multicolumn{2}{|c|}{} & Value & Approx. Sig. \\
\hline \multirow{2}{*}{ Nominal by Nominal } & Phi & -.535 & .003 \\
\hline & Cramer's V & .535 & .003 \\
\hline N of Valid Cases & 30 & \\
\hline
\end{tabular}

\section{Discussion}

The study aimed to examine whether Iranian bilingual and monolingual foreign language learners would differ in use of learning strategies while learning a foreign language. It also attempted to determine differences between Iranian monolingual and bilingual foreign language learners regarding the order of using learning strategies. The findings of the present study indicated that monolinguals and bilinguals of intermediate level were not so different in terms of using language learning strategies and both groups were considered as medium strategy users but bilinguals had to some extent an advantage to monolinguals and they used more metacognitive and cognitive strategies which were considered more important and effective ones in learning another language. Moreover, considering learning strategies monolinguals and bilinguals had a bit different preference.

The finding of the present article is in line with that of other researchers like Ramsay (1980) who discovered that multilinguals tended to perform far better than monolinguals on an achievement test.

This study was also in congruent with the ones conducted by Möhle (1989) and Bartlet (1989). Möhle (1989) examined learning strategies in German multilingual university students and found prevalent metacognitive strategy using among them. Bartlet (1989) found evidence of broad use of metacognitive and communicative strategies in oral discourse and oral narrative.

The result of this study is also in compliance with other studies such as Jessner (1999), Zobl (1992) and Klein (1995). Jessner (1999) investigated the role of metalinguistic awareness in multilinguals within the framework of the Dynamic Model of Multilingualism and argued that metalinguistic awareness is desirable and can be increased through teaching similarities between languages and through activating students' prior linguistic knowledge.

\section{Conclusion and Pedagogical Implications}

The aim of investigating language learning strategies was to produce more effective learning and the purpose behind such practices was to influence learners' language learning process so that learners' efforts as well as those of their instructors may be more fruitful. Learning strategies are used by students to help them understand information and solve problems. A learning strategy is a person's approach to learning and using information. Students who do not know or use good learning strategies often learn passively and ultimately fail in school. Learning strategy instruction focuses on making the students more active learners by teaching them how to learn and how to use what they have learned to solve problems and be 
successful. So the factors that affect learning strategy usage, and their possible benefits for language learning should be considered.

This study focused on the proficiency level of students. All the participants were at intermediate level and as mentioned before this study on lower proficiency levels such as elementary levels may indicate more distinctive differences. The results of this study showed a greater use of strategy use among bilingual learners when compared with the monolinguals. They use more metacognitive and cognitive strategies. This might be due to the success at learning previous languages and experience of learning more than one language. Moreover, bilinguals have an advantage like employing more cognitive and metacognitive strategies which are considered more important and effective in learning another language so they are more advantageous in the learning process. Wharton (2000) stated that bilinguals' use of strategies has been reinforced by previous success at acquiring or learning other languages.

On the other hand, bilinguals and monolinguals had different preferences in terms of using strategies. Bilinguals used metacognitive, cognitive, social, compensation, memory, and affective strategies, respectively, while, monolinguals used social, metacognitive, cognitive, compensation, affective and memory strategies, respectively.

\section{References}

Bartlet, G. (1989). The interaction of multilingual constraints. In H. Dechert, \& M. Raupach (Eds.), Interlingual process (pp. 5-16). Tübingen: Gunter Narr.

Brown, A. L., \& Palinscar, A. S. (1982). Inducing strategies learning from texts by means of informed self-control training. Topics in Learning and Learning Disabilities, 2, 1-17.

Ellis, R. (1985). Understanding second language acquisition. Oxford: Oxford University Press.

Ehrman, M., \& Oxford, R. (1995). Cognitive plus: correlations of language learning success. Modern Language Journal, 79, 67-89.

Hakuta, K. (1990). Bilingualism and a bilingual education: A research perspective. Focus: Occasional Papers in Bilingual Education, 1. Washington, DC: National Clearinghouse for Bilingual Education.

Jessner, U. (1999). Metalinguistic awareness in multilinguals: Cognitive aspects of third language learning. Language Awareness, 8, 201-209.

Klein, E. (1995). Second versus third language acquisition: Is there a difference? Language Learning, 45, 419-465.

Lee, C. K. (2010). An overview of language learning strategies. ARECLS, 7, 132-152.

Möhle, D. (1989). Multilingual interaction in foreign language production. In H. Dechert, \& M. Raupach (eds.), Interlingual process (pp. 179-194). Tübingen: Gunter Narr.

Naiman, N., Fröhlich, M., \& Todesco, A. (1978). The good language learner. Toronto: Ontario Institute for Studies in Education Press. 
O'Malley, J. M., Chamot, A. U., Stewner-Manzanares, G., Russo, R. P., \& Küpper, L. (1985). Learning strategy applications with students of English as a second language. TESOL Quarterly, 19, 557-584.

Oxford, R. (1989). Use of language learning strategies: A synthesis of studies with implications for strategy training. System, 17, 235-247.

Oxford, R. (1990). Language learning strategies: What every teacher should know. Boston: Heinle \& Heinle.

Oxford, R., \& Burry-Stock, J. A. (1995). Assessing the use of language learning strategies worldwide with the ESL/EFL version of the strategy inventory for language learning (SILL). System, 23, 1-23.

Oxford, R., \& Nyikos, M. (1989). Variables affecting choices of language learning strategies by university students. Modern Language Journal, 73, 291-300.

Ramsay, R. (1980). Language-learning approach styles of adult multilinguals and successful language learners. In V. Teller, \& S. White (eds.), Studies in child language and multilingualism (pp. 73-96). New York: New York Academy of Sciences.

Reiss, M.A. (1985). The good language learner: Another look. Canadian Modern Language Review, 41, 511-523.

Rivers, W., \& Golonka, E. (2009). Third language acquisition theory and practice. In M. Long and C. J. Doughty (Ed.), The handbook of language teaching (pp. 250-266). Blackwell Publishing Ltd.

Rivers, W. (2001). Autonomy at all costs: An ethnography of metacognitive self- assessment and self-management among experienced language learners. Modern Language Journal, 85, 279-290.

Rivers, W. (1996). Self-directed language learning and third-language learners. ERIC Document. ED411679.

Tamada, Y. (1996). The relationship between Japanese learners"e personal factors and their choices of language learning strategies. Modern Language Journal, 80, 120-131.

Tuncer, U. (2009). How are bilinguals and monolinguals different in use of learning strategies? Evidences from Mersin University. Procedia Social and Behavioral Sciences 1 (2009) 82-856, 1877-0428. http://dx.doi.org/10.1016/j.sbspro.2009.01.153

Vidal, R. J. (2002). Is there a correlation between reported language learning strategy use, actual strategy use and achievement? Linguagem \& Ensino, 5, 43-73.

Wharton, G. (2000). Language learning strategy use of bilingual foreign language learners in Singapore. Language Learning, 50(2), 203-243.

Vann, R., \& Abraham, R. (1990). Strategies of unsuccessful language learners. TESOL Quarterly, 24(2), 223-234. 


Mll Macrothink

Wenden, A. (1999). Metacognitive knowledge and language learning. Applied Linguistics, 19, 515-37.

Wenden, A. L. (1987). Conceptual background and utility. In A.L. Wenden, \& J. Rubin (Eds.), Learner strategies in language learning (pp. 3-13). Englewood Cliffs, NJ: Prentice-Hall.

Williams, M., \& Burden, R. (1997). Psychology for language teachers. Cambridge: Cambridge University Press.

Zobl, H. (1992). Prior linguistic knowledge and the conservatism of the learning procedure: Grammaticality judgments of unilingual and multilingual learners. In S. Gass, \& L. Selinker (eds.), Language transfer in language learning (pp. 176-96). Amsterdam/Philadelphia: John Benjamins.

\section{Copyright Disclaimer}

Copyright reserved by the author(s).

This article is an open-access article distributed under the terms and conditions of the Creative Commons Attribution license (http://creativecommons.org/licenses/by/3.0/). 